\title{
Literacy and Health Research in Canada
}

\section{Where Have We Been and Where Should We Go?}

\author{
Irving Rootman ${ }^{1}$ \\ Barbara Ronson ${ }^{2}$
}

\section{ABSTRACT}

This article reviews current literature and research on literacy and health and identifies priorities for research on this topic in Canada. Information sources included documents found through an environmental scan, the Alpha Plus collection and a computer search of recent documents. The information was analyzed using a conceptual framework. The review found that low literacy has direct and indirect impacts on health. Families are at risk due to difficulty reading medication prescriptions, baby formula instructions and health and safety education materials. People with lower levels of literacy tend to live and work in less healthy environments. They have more difficulties obtaining employment and income security. Determinants of literacy include: education, early childhood development, aging, living and working conditions, personal capacity/genetics, gender and culture. Action is needed to improve literacy and health through a combination of health communication, education and training, community development, organizational development, and policy development. There is some evidence that such interventions can have a positive effect on health, particularly when combined with one another. Further program and policy development requires greater evidence and evaluation of existing initiatives, more cost/benefit analyses, more culturally specific studies, and greater attention to current social trends and needs.

MeSH terms: Literacy; health; health literacy; research; evaluation; health promotion

La traduction du résumé se trouve à la fin de l'article.

1. Professor and Michael Smith Foundation for Health Research Distinguished Scholar, University of Victoria

2. Consultant and Fellow, Centre for Health Promotion, University of Toronto

Correspondence: Dr. Irving Rootman, Faculty of Human and Social Development, University of Victoria, PO Box 3060, Stn CSC, Victoria, BC V8W 3R4, Tel: 250-472-4102, Fax: 250-472-4836, E-mail: irootman@uvic.ca

Acknowledgements and Sources of Support: This article is based on a paper prepared for an International Think-Tank on Reducing Health Disparities and Promoting Equity for Vulnerable Populations sponsored by the Canadian Institutes of Health Research (CIHR) held September 21-23, 2003. The authors acknowledge the Reducing Health Disparities Initiative of CIHR and the Canadian Population Health Initiative of the Canadian Institute for Health Information for sponsoring the production of this article. They also thank the Social Sciences and Humanities Research Council's "Valuing Canadian Literacy" Program for their support of the project to develop a program of research on literacy and health, and the CIHR Population and Public Health, Aboriginal and Gender and Health Institutes for supporting the workshop on literacy and health research. Thanks to participants at the think-tank for their input; to the investigators on the SSHRC grant (Jim Frankish, Deborah Gordon El-Bihbety, Heather Hemming and Margot Kaszap); and to participants in the focus groups for their input into the conceptual framework for literacy and health research presented here. Particular thanks go to Jim Frankish for his constructive comments on this paper, and to the reviewer of this paper for constructive suggestions. The content remains solely the responsibility of the authors.
L iteracy and health research and practice in Canada date back to the late 1980s when the Ontario Public Health Association (OPHA) collaborated with Frontier College, the country's oldest literacy network, on a literacy and health project. Their first report, Making the World Healthier and Safer for People Who Can't Read, was published in 1989. ${ }^{1}$ Their second report, Partners in Practice, documented the increasing collaboration that their work had fostered between literacy workers, health service providers and learners. $^{2}$

In 1994, the Canadian Public Health Association (CPHA) established the National Literacy and Health Program (NLHP) with funding from the Secretary of State's new National Literacy Secretariat. Through the NLHP, CPHA has collaborated with 27 national partners to improve health services for consumers with literacy difficulties. They have carried out several projects, organized conferences and generated the publication and dissemination of countless plain language materials. The NLHP is considered to be a model for raising awareness, exploring issues, developing resource materials and building partnerships in this field. Its work helped Canada to become an international leader in literacy and health. Today, the field is at a critical juncture where further program and policy development requires greater evidence and evaluation of existing initiatives, more cost/benefit analyses, more culturally specific studies and greater attention to current social trends and needs.

Some of the trends we are facing that make this kind of work so timely are that our ethnic and linguistic make-up is changing rapidly; the use of computers and new technologies is proliferating; there are greater literacy requirements for functioning in our knowledge economy; there are unprecedented stresses on our healthcare and education systems; we have an aging population at the same time as there is a growing reliance on home and community care in place of institutional care; and Canadians are finding increasing opportunities and responsibility to provide health-care information, support and education internationally as well as locally. Finally, we urgently need multi-sectoral collaboration to solve many kinds of problems. The field of health promotion has a 
history of experience in partnership building, and literacy and health research can be a guiding light for the kind of work and methods that are needed.

In 2002, a team of researchers from across Canada, ${ }^{3}$ in partnership with the Canadian Public Health Association, was funded by the Social Sciences and Humanities Research Council (SSHRC) to develop such a program of research. They began by conducting an environmental scan of Canadian research and practice in literacy and health as well as a needs assessment. In addition, they received funding from three institutes of the Canadian Institutes of Health Research (CIHR) Aboriginal Health, Gender and Health, and Population Health - to organize a workshop (the "national workshop") to present the findings of the environmental scan and needs assessment and define a national agenda for further research. ${ }^{4}$ Figure 1 shows key milestones in the development of the field in Canada.

This article is an attempt to provide an overview of where we have been and a projection of where we should go in literacy and health research in Canada. Specifically, the objectives of this article are to:

1. review existing literature and research on the impact of literacy on health, on the determinants of literacy, and on the effectiveness of interventions to improve health through improving literacy; and

2. identify priorities for research on literacy and health in Canada.

The approach to reviewing the literature used in this article was to employ a conceptual framework developed by the authors and collaborators to identify relevant literature and research and examine it carefully to determine the extent to which it supports the framework. A MEDLINE search was carried out to identify relevant literature using the terms literacy, literacy and health, and health literacy. Computer searches also identified relevant literature through the search engine Alta Vista and through the Alpha Plus collection in Toronto using the terms "literacy" and "health". In addition, sources identified in the NHLRP key informant survey were examined. Existing reviews, particularly those conducted by Perrin ${ }^{5}$ and Rudd and her colleagues ${ }^{6}$ and those carried out for the US Institute of Medicine report on Health Literacy ${ }^{7}$ were used as well.

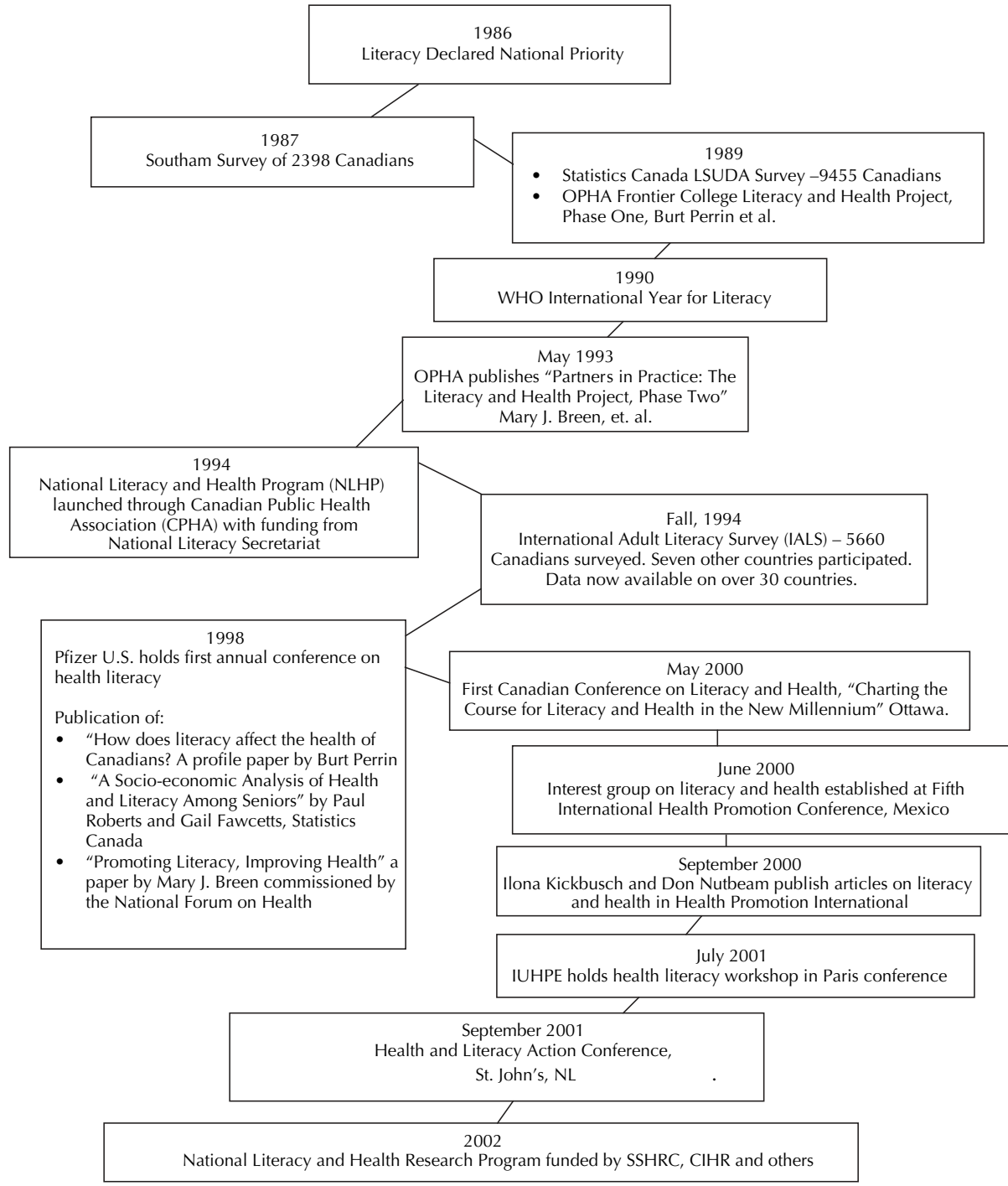

Figure 1. Milestones in literacy and health research in Canada

With regard to identifying priorities for research in Canada, the conclusions of the above-mentioned environmental scan and needs assessment and national workshop were considered, as well as recommendations in the literature and research that were reviewed.

\section{Conceptual framework for literacy and health research}

One of the first steps of the National Literacy and Health Research Program was to develop a conceptual framework for literacy and health research based loosely on the work carried out for the OPHA and Frontier College project. $^{5}$ An initial framework was discussed in four focus groups across the country and revisions were made based on the feedback received at the focus groups as well as at the national workshop. The resulting framework is shown in Figure 2.
In the middle of the diagram, under the heading "Literacy" we find "general literacy", "health literacy" and "other literacies". General literacy includes reading and listening ability, numeracy, speaking ability, negotiation skills, critical thinking and judgment. Health literacy is thought to include the ability to find, understand and communicate health information and to assess it. Other literacies are thought to include computer literacy, cultural literacy, media literacy and scientific literacy.

To the right of the literacy box are a number of possible direct and indirect effects of literacy on health. Direct effects include medication use and safety practices; indirect effects include use of services, lifestyles, income, work environment and stress levels. In the bottom left-hand box of the framework are a number of possible determinants of literacy including 


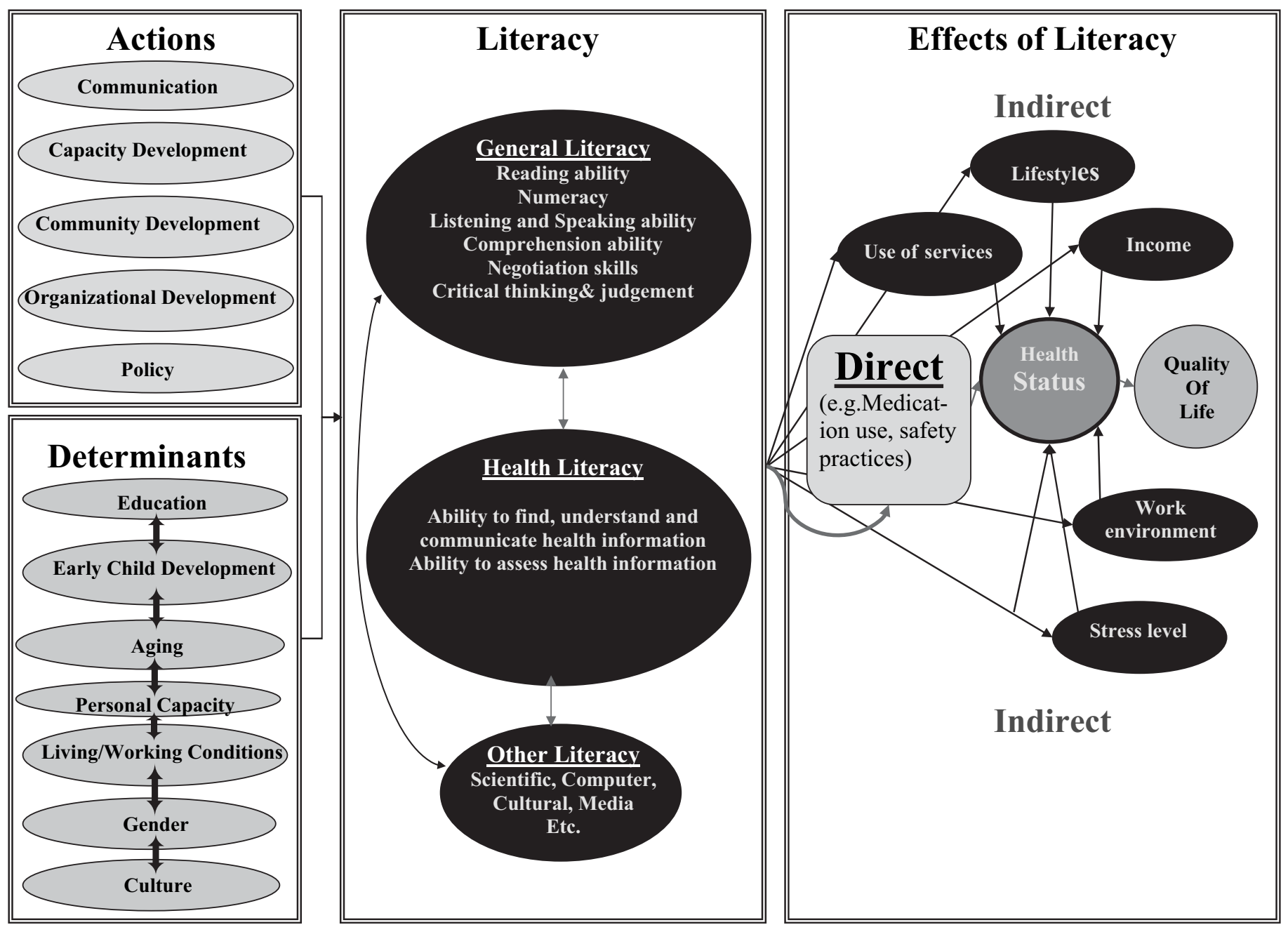

Figure 2. Conceptual framework for literacy and health research

education, early childhood development, aging, personal capacity, living and working conditions, gender and culture. Finally, in the top left-hand box are a number of types of actions (health communication, health education, community development, organizational development and policy development), which might be used to address literacy and health issues. This conceptual framework was used to review the relevant literature.

Specifically, the following sections cover the main components of the framework. That is, the next section focusses on the "literacy" component by covering the definition and measurement of literacy and health literacy and the relationships between the different types of literacy. The section after that focusses on the "effects" component, covering both direct and indirect effects. The one following that on the "determinants" component covers all of the determinants listed. The penultimate section of the article reviews what we know about the four research priorities suggested by the national workshop, namely: effectiveness of interventions; cost-benefit studies; Aboriginal and francophone communities and culturally diverse and challenged groups; and literacy, life-long learning and health. The final section presents conclusions and recommendations for research and practice.

\section{Defining and measuring "general literacy"}

Historians estimate literacy rates in other times by the number of people who signed their marriage certificates with an $\mathrm{X}$ in church records. Immigration authorities in Canada and the US were known to test literacy by having applicants read a passage from a book, and those who couldn't were often turned back. In the $1950 \mathrm{~s}$, UNESCO portrayed literacy as a continuum of skills, suggesting two levels for international comparison: a minimum level marked by the ability to read and write a simple passage; and a functional level demonstrated by literacy sufficiently high for the person to function in society. Over 110 countries have used UNESCO's simple definition that "a person is literate who can with understanding both read and write a short simple statement on his everyday life." ${ }^{8}$ Because it is so timeconsuming and expensive to test large numbers of citizens, literacy rates have commonly been estimated across countries based on years of schooling. But the skills needed to be literate have increased as more children and youth spend more years in school. UNESCO suggests that "[a] person is functionally literate when he [sic] has acquired the knowledge and skills in reading and writing which enable him [sic] to engage effectively in all those activities in which literacy is normally assumed in his [sic] culture or group." ${ }^{8}$ It is now estimated that students in western countries who have less than nine years of schooling have not achieved sufficient skills. 
Progress has been made in developing and using measures of "functional literacy" within and across countries. In 1974, the US Office of Education defined 11 skills for functional literacy, such as reading and understanding all sections of a newspaper; reading a driver's licence test; and reading business letters from debtors and creditors. The Adult Performance Level Study ${ }^{9}$ defined four basic areas of skills proficiency: communication, computation, problem solving and interpersonal skills. These were tested across five knowledge areas: occupational, consumer economics, community resources, government and law, and health. A 1987 Southam survey in Canada ${ }^{10}$ was based on a functional definition of literacy and items were selected from a US National Assessment for Educational Progress instrument and amended for a Canadian audience. A panel of diverse professionals as well as learners rated each item in order to determine a definition of "literacy". Eighty percent of the panel had to agree in order for an item to be included as critical for literacy.

In 1992, the literacy level of 26,000 adults across the US was tested by the Educational Testing Service in a National Adult Literacy Survey (NALS). ${ }^{11}$ This survey was also based on a functional definition of literacy and participants were assessed on a five-point scale. In 1994, Human Resources Development Canada and others funded the International Adult Literacy Survey (IALS) using a similar instrument that assessed "prose", "document" and "quantitative" literacy on a fivepoint scale (see Table I). Originally a seven-country initiative, data are now available from more than 30 countries. The IALS is now the main source of measures of literacy in the general population in Canada and in other countries. ${ }^{12}$ The latest figures (1994-95) show that $48 \%$ of Canadian adults fall into the lowest two categories. Twenty-two percent of adults have serious literacy challenges, and another $26 \%$ do not have the literacy skills necessary to participate fully in the "knowledge economy" ${ }^{13}$ Figure 3 illustrates the literacy levels of Canadian adults over age 16.

In the US and Canada, concerns have grown that longer years in school among today's students have not been associated with rising standards of literacy or skills needed to succeed in the present "knowl-

\section{TABLE I}

\section{Kinds of Literacy Measured in the International Adult Literacy Survey}

Prose literacy:

Reading and understanding text in sentences and paragraphs.

Document literacy: Using and understanding maps, charts, forms and other documents.

Quantitative literacy (or Numeracy): Using numbers for daily tasks such as balancing a cheque book, calculating a tip, completing an order form, or determining the interest on a loan.
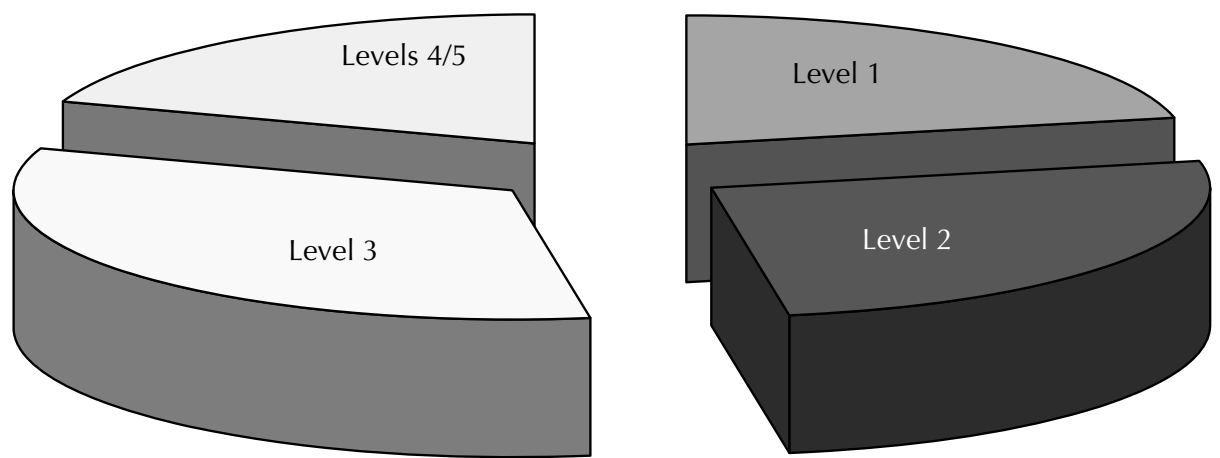

Level 1 A person is not able to read at all or has very serious problems with reading (22\%)

Level 2 A person can read simple language $(26 \%)$

Level 3 A person can read well enough to get along from day to day $(33 \%)$

Levels $4 \& 5$ People can read complex reading material $(20 \%)$

Figure 3. Literacy level of Canadian adults over age 16

Source: International Adult Literacy Survey, 1994

edge economy". This has led to widespread literacy testing in schools. In Ontario, approximately 95\% of all Grade 3, 6 and 10 students have been tested in the past four years. ${ }^{14}$ That amounts to hundreds of thousands of young Ontarians participating each year, far more than the 2,398 of the 1987 Southam survey, the 9,455 of the 1989 Survey of Literacy Skills used in Daily Activities (LSUDA) survey or the 5,660 in the 1994 IALS. Results of these tests on children and youth have recently become available and will undoubtedly add fuel to the interest in literacy studies in general and literacy and health studies in particular. In Ontario, a passing score on the Grade 10 literacy test has become mandatory for high school graduation. Only recently have there been alternatives proposed for the $20 \%$ or more unlikely to ever pass the test. The impact of the testing has been massive but as yet there has been little research into its impact on health and learning of our young people.

When regional, international and school comparisons are not important, more flexible definitions of literacy meaningful to individual learners are preferred, at least when it comes to adults. Freire's highly influential book, Pedagogy of the Oppressed, ${ }^{15}$ describes literacy as an active phenomenon, deeply linked to personal and cultural identity. His work helped transform understanding of literacy from a received ability to read and write to an individual's capacity to put those skills to work in shaping the course of his or her own life. ${ }^{16}$ Sticht differentiated externally imposed literacy tasks from internally imposed tasks and defined functional literacy as "the possession of those literacy skills needed to perform some reading task imposed by an external agent between the reader and a goal the reader wishes to obtain." 17 This definition fits within a health promotion framework. The Ottawa Charter for Health Promotion ${ }^{18}$ defines health promotion as the process of enabling people to gain control over their health. The related concept of empowerment is considered to be the key mechanism of health promotion. Literacy can be one means of personal empowerment and gaining control over one's own health if it is internally imposed. Many Aboriginal texts on literacy have adopted the term empowerment as fundamental for literacy and learning. ${ }^{19-21}$ 
With the advent of functional, needsbased approaches, the definition of literacy may always be a moving target. People have begun speaking in terms of "literacies" not "literacy" and to promote "media literacy", "computer literacy", "health literacy" and the like, instead of a discrete concept of something one either has or does not have. ${ }^{22}$ New technologies, bilingualism, multiculturalism and the renaissance of Aboriginal culture in Canada have pushed the meaning of literacy beyond reading, writing and numeracy skills in one official language. Schools that are mainly defined in terms of "reading, writing, and 'rithmetic" may similarly be obsolete. New technologies have given wide access to means of learning other than printed books, pamphlets, lectures and face-to-face conversations - the predominant options a century ago. Cultural pluralism has made us more aware of oral cultures and languages not linked to the alphabet. Leu writes, "if there is one thing that is certain in these uncertain times, it is that the technologies of information and communication will regularly and repeatedly change, regularly redefining what it means to be literate." 23

Shohet of the Centre for Literacy, Québec concurs: "Electronic media are changing the nature of literacy and forcing a convergence of print, the visual, and the oral." 22 The Centre for Literacy defines literacy as "a complex set of abilities to understand and use the dominant symbol systems of a culture for personal and community development." 24

Aboriginal literacy has been defined by a coalition of Aboriginal literacy specialists in terms of colours of the rainbow:

- red represents literacy in the language of origin of First Nations individuals and communities

- orange - oral literacy

- yellow - creative means of communicating with speakers of other languages using symbols, artwork and sign language

- green - the languages of the original European newcomers, French and English - now Canada's official languages

- blue - technological literacy; and

- violet - balance, the holistic base to Aboriginal literacy, dealing with spiritual, emotional, mental and physical elements. ${ }^{25,26}$
The Ontario Native Literacy Coalition defines Native literacy as (p.10): ${ }^{25}$

"...a tool which empowers the spirit of Native people. Native literacy services recognize and affirm the unique culture of Native Peoples and the interconnectedness of all aspects of creation. As part of a life-long path of learning, Native literacy contributes to the development of self-knowledge and critical thinking. It is a continuum of skills that encompasses reading, writing, numeracy, speaking, good study habits, and communicating in other forms of language as needed. Based on the experience, abilities and goals of learners, Native literacy fosters and promotes achievement and a sense of purpose, which are both central to self-determination."

The future of literacy in Canada may be one of multiple literacies with multiple definitions and measures, although at the moment, the official definition of literacy is the one used by the IALS, namely: the "ability to understand and employ printed information in daily activities - at home, at work and in the community - to achieve one's goals and develop one's knowledge and potential." 12

\section{Defining and measuring "health literacy"}

Although the term "health literacy" was first used in health education about 30 years ago, ${ }^{27}$ it has only recently been taken seriously as a field of inquiry. In 1998, Pfizer U.S. held its first annual conference on health literacy. The Institute for Healthcare Advancement in the U.S. started annual conferences on health literacy in 2001. An ad hoc Committee of the American Medical Association defined functional health literacy as "the ability to read and comprehend prescription bottles, appointment slips, and other essential health-related materials required to successfully function as a patient." ${ }^{28}$ The U.S. Department of Health and Human Services defines it as "the capacity to obtain, interpret and understand basic health information and services and the competence to use such information and services to enhance health." 29 The US government's Healthy People 2010 describes it as "the degree to which individuals have the capacity to obtain, process, and under- stand basic health information and services needed to make appropriate health decisions." 30 This was the definition that was adopted by the Institute of Medicine Committee on Health Literacy.

The Rapid Estimate of Adult Literacy in Medicine (REALM) and the Test of Functional Health Literacy in Adults (TOFHLA) are the main tests for health literacy. Both of them are really tests of reading ability in a health context and ignore oral and aural literacy. When the TOFHLA was administered to 2,659 predominantly indigent, minority emergency room patients at two public hospitals in the US, $41.6 \%$ were unable to comprehend directions for taking medication on an empty stomach; $26 \%$ were unable to understand information regarding when to come for a next appointment; and 59.5\% could not understand a standard informed consent document. More than $80 \%$ of both English- and Spanish-speaking patients over 60 years of age were found to have inadequate or marginal health literacy. This is significantly more than younger English- and Spanish-speaking patients of whom $31 \%$ and $62 \%$ had inadequate health literacy respectively. ${ }^{31}$ We do not yet know, however, how many of these patients could comprehend directions given orally as opposed to in writing, nor how many were able to find information they needed in other ways. It is conceivable that people can be functionally health literate with minimal reading and writing skills, depending on how health literacy is defined.

A health promotion interest group on health literacy involving participants from different countries has been established and a series of meetings and workshops have taken place to help conceptualize health literacy. One of these was held at the Fifth International Conference on Health Promotion in Mexico (June 2000). This group has generated still more interest in health literacy among health promotion practitioners, as indicated by continued publications on this topic particularly in the Health Promotion International journal. A proposed redefinition of health literacy that goes beyond functional aspects is found in a 1998 revision of the WHO glossary of health promotion terms. Health literacy is described there as "the cognitive and social skills which determine the moti- 
vation and ability of individuals to gain access to, understand, and use information in ways which promote and maintain good health" [emphasis added]. ${ }^{32}$ In addition, the glossary notes that " $[\mathrm{h}]$ ealth literacy means more than being able to read pamphlets and successfully make appointments. By improving people's access to health information and their capacity to use it effectively, health literacy is crucial to empowerment." 32 Building upon the redefinition of health literacy to encompass concepts of empowerment, Nutbeam ${ }^{33}$ defined three levels of health literacy:

1. Basic/functional: "sufficient basic skills in reading and writing to be able to function effectively in everyday situations."

2. Communicative/interactive: "more advanced cognitive and literacy skills which, together with social skills, can be used to actively participate in everyday activities, to extract information and derive meaning from different forms of communication, and to apply new information to changing circumstances."

3. Critical literacy: "advanced cognitive skills which, together with social skills, can be applied to critically analyze information, and to use this information to exert greater control over life events and situations."

Nutbeam and others have suggested that health literacy is a key outcome of health education and one that health promotion could legitimately be held accountable for. Some scholars, however, have questioned the utility of redefining health literacy. For example, according to Keith Tones, editor of the journal Health Education Research, "the kind of territorial expansion involved in translating limited, but clearly defined concepts into much broader, semantically unrelated constructs is both unnecessary and counter productive." ${ }^{34}$ The debate is a healthy one and should continue. ${ }^{35}$

Although we have come a long way in understanding, defining and measuring literacy and health literacy, there is still much to be done. As mentioned, the TOFHLA and REALM measure only a limited range of capacities associated with health literacy and, with the exception of the TOHFLASpanish version, are in English only. There are no contextual measures. Similarly, the IALS measures only a limited number of components of literacy (prose, document, quantitative) and misses others (e.g., oral and aural). Thus, measures for literacy and health literacy today are inadequate and new ones need to be developed. This was one of the key conclusions of the recommendations of the recent Institute of Medicine (IOM) Committee on Health Literacy. $^{7}$

\section{Correlations between literacy, health literacy and other literacies}

No population survey has measured the relationship between literacy and health literacy. However, correlations between existing measures of literacy and of health literacy suggest an association ${ }^{36}$ and the correlates of literacy are similar to those of health literacy ${ }^{6}$ suggesting that they are strongly, but not perfectly, related to each other. With regard to other literacies, no studies were found that statistically examined the relationships with either general literacy or health literacy. Thus, we clearly need more research on the relationships between literacy, health literacy and other literacies in understanding literacy and health.

\section{Effects of literacy}

\section{Direct Effects}

There is evidence in the literature that literacy is directly related to overall health status and mental health status ${ }^{37-39}$ as well as co-morbidity burden. ${ }^{40}$ In addition, lowliterate consumers and their families appear to be at risk of harm due to their difficulty reading medication prescriptions, baby formula instructions and other written material. ${ }^{41}$ The direct effects of literacy on health are a matter of concern for all health-care providers. If their communications and instructions are not helpful, and are potentially harmful for up to one-half of their clients, addressing the problem should be a priority. Primary concerns are with medication use, compliance with physician orders $^{42}$ and with chronic-condition management. ${ }^{43}$ Concerns relate not only to health-service providers' professional effectiveness but also to the costs to the system of drug benefit plans and medical insurance when prescription drugs are misused and patients are unable to follow directions properly. Particularly unsettling is the fact that seniors are among the least literate groups in society and also the most heavily dependent on medications and health services. $^{39}$

Literacy should also be of concern to employers, manufacturers and retailers who handle potentially dangerous products and processes. Direct effects of literacy on health also occur in workplaces and other settings where safety may be dependent on one's ability to read rules, signs and manuals. A Manitoba review of literacy and health, for example, indicated that "difficulty comprehending precautions on farm and recreational machinery such as allterrain vehicles, water sleds, snowmobiles and farm equipment of all sorts, makes rural life more dangerous." ${ }^{44}$ The Canadian Business Task Force estimated that of the $\$ 4$ billion lost by business due to literacy problems, $\$ 1.6$ billion is attributable to workplace accidents. ${ }^{45}$ Edwards ${ }^{46}$ found that The Workplace Hazardous Materials Information System consists of text often written at the college level. In addition, there is evidence that occupational injuries, the degree of awareness of the dangers in the workplace, and installation of home safety features are associated with limited literacy. ${ }^{42}$

\section{Indirect Effects of Literacy}

Research suggests that literacy has an impact on lifestyle practices. For example, an Australian study of students in primary schools found that low literacy predicted tobacco use among both boys and girls and alcohol use among boys. ${ }^{47}$ Similarly, a study in the United States found that low literacy was associated with choice of contraceptive methods as well as knowledge about birth control. ${ }^{48}$ In addition, there is much evidence that education has a powerful influence on a range of personal lifestyle choices. ${ }^{49}$

Literacy is clearly linked to income. People with limited literacy skills are more likely to have lower incomes than those with greater skills. ${ }^{13,50}$ People with limited literacy are more likely to be unemployed and to be working for minimum wage in unskilled jobs and are also more likely to be working in older industries. ${ }^{12}$ Literacy is related to type of employment. Highest literacy levels in the LSUDA study were found in the teaching, science, engineering, social science and managerial professions $(85-92 \%$ of respondents tested at the highest of 4 literacy levels). The greatest 
proportion of respondents testing at the lowest literacy levels were in the product fabricating, service and farming sectors. ${ }^{51}$

People with limited literacy also have less knowledge about medical conditions and treatment ${ }^{52}$ and they have trouble understanding health issues generally. ${ }^{6}$ They also have more difficulty with verbal communications from practitioners. ${ }^{43}$ Overall, they have higher stress levels and feelings of vulnerability. ${ }^{42}$

Considerable research to date discusses the impact of literacy on use of services. People with lower literacy levels tend to be less aware of and make less use of preventive services. ${ }^{53}$ They are also less likely to seek care, ${ }^{54}$ they have higher rates of hospitalization, ${ }^{55}$ and they experience more difficulties using the health-care system. ${ }^{56,57}$ Research also suggests a link between low levels of literacy and increased health-care costs. The IOM Health Literacy Committee, drawing on the limited amount of data available, suggested that "there is an association between health literacy, health-care utilization and health care costs" (p. 9). ${ }^{7}$ There are no cost estimates available based on Canadian data, however. There is also little research on the relationship between literacy, health literacy and quality of life in the health literature, although much progress has been made in developing measures of quality of life. ${ }^{58}$

\section{Determinants of literacy}

Current literature on health promotion and population health focus on a number of determinants of health. The newly established Public Health Agency of Canada lists the following determinants of health: income and social status; social support networks; education and literacy; employment/working conditions; social environments; physical environments; personal health practices and coping skills; healthy child development ; biology and genetic endowment; health services; gender; and culture (see www.phacaspc.gc.ca/ph-sp/phdd/determinants).

Because health and learning are so inextricably connected, the same factors may also be determinants of literacy. In fact, literacy itself is listed here as a possible determinant of health. However, it is also an outcome of education and may be an outcome of other determinants of health. For the sake of this review, seven determinants have been selected by the authors as particularly relevant: education, early childhood development, aging, personal capacity, living and working conditions, gender, and culture. It should be noted, however, the evidence to date linking these determinants to literacy is mostly correlational. The extent to which they are causal remains to be determined by further research.

\section{Education}

There is a strong relationship between educational level and literacy. ${ }^{12}$ However, education and literacy are not perfectly correlated, and literacy itself is a strong predictor of health. ${ }^{39}$ In fact, recent studies have suggested that literacy skills predict health status even more accurately than education level, income, ethnic background, or any other socio-demographic variable. ${ }^{59-61}$ In international studies, this determinant is often estimated by years of schooling, or highest grade level achieved. However, there is potential for serious error bias in literacy estimates based on years of schooling that do not control for a wider set of socio-demographic factors and the quality of years of schooling. ${ }^{62}$ There are many examples of discordance between years of schooling and literacy at the individual level. Nevertheless, as noted above, it is clear that education is a major determinant of literacy, which led the Institute of Medicine Committee on Health Literacy to posit the education system as one of three main points of intervention in relation to influencing the level of health literacy in individuals and in the population.?

\section{Early Childhood Development}

Recent research in brain development has drawn attention to findings that indicate highest capacity for learning in the early years. Studies show a "hard-wiring" of the brain over time that affects capacity for future learning, emotional patterns, lifelong attitudes and problem-solving approaches. ${ }^{63,64}$ Early child development programs, moreover, have proven capacity for breaking inter-generational cycles of disadvantage and dramatically improving chances of high school graduation, workplace participation, etc. ${ }^{65}$ The critical period for learning a first language is thought to be between birth and three years of age. Learning a second language becomes more difficult after age $10 .^{66}$ Thus, it is clear that early childhood development can make a significant contribution to the development of literacy.

\section{Aging}

Seniors tend to have higher rates of low literacy $^{12,39}$ and literacy levels appear to decline with age. For example, Baker and his colleagues found that health literacy among community-dwelling seniors declined with age after controlling for other factors such as mental state, newspaper reading frequency, health status and visual acuity. ${ }^{67}$ In another study, reading ability declined dramatically with age even after adjusting for years of school completed and cognitive impairment. ${ }^{48}$ Thus, it appears that literacy is not something which, once attained, stays forever. Many seniors, especially those who do not read habitually, lose their skills and have great difficulties with labels on medications, for example. This has other consequences as well. For example, studies - mostly by Baker and his colleagues - found that low health literacy among older adults was related to lower mental health scores, higher rates of hospitalization, poorer selfreported health, and less use of preventive health services such as vaccinations. ${ }^{37,38,68}$

\section{Personal Capacity}

Both early childhood development and aging contribute to personal capacity for learning and literacy. Similarly, perceptual or cognitive difficulties, and disabilities (e.g., sight, hearing or learning) are barriers to literacy. ${ }^{69}$ It has been estimated that about one third of participants in literacy programs has a learning disability. ${ }^{70}$ Biology and genetics likely also play some role. For example, individuals with the genetically related condition of Downs syndrome have greater difficulty mastering literacy skills. Much progress has been made in differentiating learning styles. Little research has been done to date, however, to apply new methods of genetic research towards a better understanding of learning styles.

\section{Living and Working Conditions}

According to the Canadian component of the IALS survey, between $22 \%$ and $50 \%$ of adults with lower levels of literacy live in low-income households, compared with only $8 \%$ of those with high-level literacy 
skills. ${ }^{39}$ Children of parents with reading problems are more likely to have reading problems themselves. ${ }^{71}$ In the 2000 Program for International Skills Assessment (PISA), parental attitudes towards academics were found to be a key variable: students with a home environment that stimulated learning did better than all other students in all countries. Students with parents who took them to a variety of cultural events and who discussed current affairs outperformed other students in all countries. As well, students who enjoyed reading, borrowed books from a library and had high career aspirations, did better than other students. ${ }^{72}$ Violence and abuse, on the other hand, are key threats to learning capacity. Women in literacy programs have identified men's violence (or its threat) as the greatest barrier to their learning. ${ }^{73}$ Violence and abuse undoubtedly affect children's capacity for learning as well, and are key reasons why young people do not complete high school and/or run away from home. According to the National Longitudinal Survey of Children and Youth, students who reported bullying behaviours "sometimes" or "often" scored significantly lower in math and reading scores than those who reported no bullying behaviour. ${ }^{72}$ Thus, living and working conditions clearly affect people's ability to learn and consequently, their literacy levels.

\section{Gender}

In less developed countries, women tend to have lower levels of literacy than men. ${ }^{60}$ One of the strongest predictors of life expectancy among developing countries is adult literacy, particularly the disparity between male and female adult literacy, which explains much of the variation in health achievement among these countries after accounting for gross domestic product per capita (GDPpc). For example, among the 125 developing countries with GDPpcs less than $\$ 10,000$, the difference between male and female literacy accounts for $40 \%$ of the variation in life expectancy after factoring out the effect of GDPpc. ${ }^{74}$

Literacy rates for Canadian adult men and women are comparable, but lower literacy is more prevalent among immigrant women than men. ${ }^{75}$ Nearly one third $(32 \%)$ of foreign-born women have extreme difficulty dealing with printed material or can use printed words only for limited purposes (levels 1 and 2) compared to about one quarter (24\%) of foreignborn men and approximately one tenth of Canadian-born women and men. ${ }^{75}$ Although most recent surveys of adult literacy show comparable literacy rates for men and women, ${ }^{10,13}$ school-aged girls, at least in Ontario, in Grades 3, 6 and 10 consistently score higher than boys. ${ }^{14}$ Girls performed significantly better than boys on reading tests in all countries in the 2000 PISA. ${ }^{76}$ The average score for 15 -year-old Canadian females was 32 points above that of the males. In Ontario, girls scored on average 548 and boys 418. Nationally, $40 \%$ of Canadian girls reported reading at least 30 minutes a day for enjoyment compared to about $25 \%$ for boys. Still, both genders scored at level three on a scale of one to five "capable of solving reading tasks of moderate complexity such as locating multiple pieces of information, making links between different parts of a text, and relating it to familiar everyday knowledge" (p.27). ${ }^{72}$ There is some evidence that such gaps have narrowed in adulthood as women in domestic roles may require fewer skills than men in the workplace, but it remains unclear whether such trends will continue as women play a larger role in the workplace and men take on more domestic responsibilities.

\section{Culture}

The Institute of Medicine report on health literacy defines culture as "the shared ideas, meanings, and values that are acquired by individuals as members of a society" (p.9). ${ }^{7}$ According to the report: "[d]iffering cultural and educational backgrounds between patients and providers, as well as between those who create health information and those who use it, may contribute to problems in health literacy" (p.9). Thus, one of the conclusions reached by the committee that produced the report was that " $[\mathrm{h}]$ ealth literacy must be understood and addressed in the context of language and culture" (p.10). The same is true for general literacy. In Canada, we must take cultural background seriously in addressing issues related to literacy and health. In particular, we need to pay attention to cultural groups whose ideas, meanings and values differ from the dominant culture.
Francophones, Aboriginal peoples and immigrants tend to have lower literacy scores in Canada. ${ }^{51}$ For the francophone community, differences tend to disappear among the younger generations. In the US, racial and ethnic minority populations, including Aboriginals and Spanish-speakers, are more likely than others to have lower literacy and health literacy scores. ${ }^{11,37,77}$

There is growing evidence that cultural connectedness or belonging enhances capacity to learn and can also be an incentive for learning. DeWit and his colleagues $^{78}$ found a relationship between sense of school membership and achievement. Qualitative evidence for the connection between culture and literacy abounds. For example, Traditional teacher Jim Dumont explains (p.16): ${ }^{19}$

"Native people want to know what their culture is. Native people want to know what their history is. Native people want to know what their traditions are and what their spirituality is. That's the phenomenon of our times. So if that's the case, then why not use a program such as [literacy] to provide that to them? And use that as the motivating factor in developing literacy amongst our people.... The desire to learn about those things becomes the foundation, the foundation of the literacy program."

\section{Research needed}

A number of specific topics have been identified in the literature as requiring further attention. For example, the following have been identified by various individuals and organizations as being of some priority:

- costs of health-care delivery related to direct and indirect impacts of literacy ${ }^{6,28,42}$

- longitudinal studies of potential changes in health status following changes in literacy skills ${ }^{2}$

- effective communication approaches for health providers ${ }^{28,42}$ and effectiveness of alternative forms of health communications ${ }^{6,42}$

- evaluation of promising approaches and practices (e.g., community development. and participatory education) addressing literacy and health issues ${ }^{42}$

- study of consent documents and the consenting process ${ }^{6}$

- development and testing of strategies to address the special needs of those with low health literacy ${ }^{6}$ 
- the role of literacy and other factors in enabling people to feel more confident and empowered to take action regarding their own health ${ }^{42}$

- understanding the causal pathway of how literacy influences health ${ }^{28}$

- developing new measures of literacy and health literacy ${ }^{\top}$

- the impact of literacy testing on health and learning of young people.

Fortunately, many of these topics fall under the four priority areas identified by the National Workshop on Literacy and Health Research: ${ }^{4}$ a) evaluating the effectiveness of interventions; b) conducting cost-benefit analyses; c) studying literacy and health within the unique circumstances of the Aboriginal and francophone communities, and culturally diverse and challenged groups; and d) studying the relationship between literacy, life-long learning and health. The academic literature reinforces the legitimacy of the four priority research areas named at the national workshop. Each will be examined further below.

\section{Effectiveness of interventions}

In order to advance the field of literacy and health, it is important to know what is already working well and build on that. As suggested by the conceptual framework, interventions addressing literacy and health concerns include health communication, education/training (capacity development), community and organizational development, and policy development. Unfortunately, there are few rigorous studies in the published literature to evaluate the effectiveness of any of these types of literacy and health interventions. Moreover, we have no clear consensus definitions of success for interventions and few, if any, standards for health literacy.

\section{Health Communication}

Health communication concerns ways of distributing health information to the public to change health behaviour practices. This is the approach that has attracted the most attention from researchers. Even so, very few of the studies would meet the highest standards of rigor. One exception is a randomized controlled trial (RCT) by Davis and his colleagues which compared the use of a simplified polio vaccine brochure with the regular version by parents bringing children to a pediatric care facility and found that those who read the simplified one had significantly higher comprehension than those who read the regular one. ${ }^{79}$ However, parents with the lowest reading levels did not show increased comprehension. Another RCT compared the use of a booklet and a videotape with no intervention and found that those who received the booklet or the videotape showed increased knowledge in comparison to the controls. ${ }^{80} \mathrm{~A}$ third RCT examined the effectiveness of an interactive videodisc program on self-care and found that intervention patients reported greater self-care ability. ${ }^{81}$ In addition, literacy level did not affect the amount of selfcare ability gained, which suggests that this approach was effective with people with lower literacy levels. Finally, a RCT comparing an illustrated brochure with a non-illustrated version found that there was no overall difference in comprehension, but that the illustrated brochure was better understood by patients with lower literacy, suggesting that this was another approach that was effective with persons with low literacy. ${ }^{82}$ Thus, although the findings of these studies are somewhat mixed, they do provide some encouragement to those who wish to use improved communication as an approach to addressing issues concerning literacy and health. And indeed, this is probably the most popular approach. However there is a need to encourage the use of more rigorous approaches to evaluating these kinds of interventions, and to compare this approach to other methods and to mixed methods.

It should also be noted that many studies in the United States have found that there tends to be a mismatch between the reading level of health materials and that of those expected to read them and that interventions to make such materials easier to read have had mostly positive effects. ${ }^{6}$ Only two published Canadian studies in the literature evaluate the readability of health materials. ${ }^{83,84}$ The most recent study found that the reading level of 120 educational pamphlets used in a primary care practice in Montreal was Grade 11.5, which would make the majority of the materials inaccessible to patients with low levels of literacy. ${ }^{84}$

More effective communication approaches for health providers are called for ${ }^{42}$ but at this point there are few studies of the effectiveness of alternative forms of health communications beyond the brochure. It has been suggested that we especially need to know how to most effectively transmit complex health information to patients with poor functional health literacy $^{85}$ and how to use new information technologies for this purpose. ${ }^{86}$

\section{Education and Training}

Education and training is another important approach to addressing literacy and health issues. Again, there is not much rigorous research to draw on. We were, however, able to locate three intervention studies that used randomized trials involving literacy. The first was a comparison of videotapes for diabetic persons with low literacy with monthly group sessions without videotapes. ${ }^{87}$ Both approaches appeared to be associated with short-term weight change, but not with knowledge change. A second study examined a comprehensive disease management program and found that the educational intervention appeared to be successful in reducing the effects of low literacy. ${ }^{88}$ The third, which tested a combined approach including a personal recommendation, brochure, interactive educational and motivational program, and a video found that the combined approach was associated with mammography use six months later, controlling for literacy and other factors. ${ }^{89}$ Thus, it does appear as if there is some evidence to support the use of educational approaches in reducing the effects of low literacy on health, especially if a combination of interventions is used.

Mary Norton, Eileen Antone, Tammy Horne, Pat Campbell and Mary Breen are some of the Canadian literacy specialists who have written about literacy, health and participatory education based on practical experience. Participatory approaches involve learners in issue selection and content development. Examples of participatory development of health information were found in the Canadian needs assessment. ${ }^{3}$ One example is a video and discussion guide called A Better You: The Benefits of a Healthy Lifestyle produced by the Dartmouth Literacy Network in Nova Scotia. Another example is Heart Health Nova Scotia's work on Literacy and Health Promotion: Four Case Studies. A third is the 
Canadian Public Health Association's What the Health!, a health literacy text that was collaboratively produced by youth at risk. An example of one of many Aboriginal texts is the United Native Friendship Centre's Personal Growth Manual. However, these and other efforts are yet to be evaluated.

Researchers have helped increase our understanding of the need to design education/training programs based on learners' interests and motivations. Participants in the LSUDA study who indicated an interest in upgrading programs were asked what topics most appealed to them. Improving writing skills received the widest support, not only overall, but among respondents of all literacy levels. These data suggest that writing in and of itself is a matter of concern to all Canadians. ${ }^{90}$ However, literacy programs to date have tended to focus on reading first.

\section{Community Development}

There are no studies of the effectiveness of community development in relation to literacy and health using a randomized control trial design. Nor should we expect that there should be such studies; not only is it virtually impossible to use such an approach to evaluating community development, but it is inappropriate to do so. ${ }^{91}$ However, there are an increasing number of community development projects involving literacy that use a participatory approach to evaluation. For example, health and literacy expert Marcia Drew Hohn was funded to conduct a two-year participatory action research project in partnership with a student action health team. Qualitative evidence suggested changes in action related to health, perceptions of self and "voice". ${ }^{92}$ Her project became a model for Student Action Health Teams across the state in which the project took place.

Health Canada has suggested that there is a need to consider a wider range of promising approaches to literacy and health issues such as community development. ${ }^{42}$ Nutbeam's definition of "critical health literacy" encompasses the ability to understand the importance of and act on not just personal health but wider community health concerns. Literacy advocate Sylvia Maracle of the Wolf Clan, Tyendinaga demonstrates such understanding: ${ }^{19}$
"I think that literacy is a community development process. And I think that as a community development process, it will result in empowerment. In empowering people to make educated decisions about their lives and to do that in the context of being able to assess it in the context of other people's lives."

There has been a growing interest in the role of Freirian theory in health promotion enabling people collectively to move beyond feelings of powerlessness and assuming control in their lives. ${ }^{93}$ An example in Ontario of a literacy program initiative that depicts this philosophy is a video on "goal setting" collaboratively produced by learners and staff at a program in Guelph, Ontario. ${ }^{94}$ In this video learners describe their motivation for changing their lives, the challenges they encountered and the ways they overcame their challenges.

A number of resources have recently been developed that can enhance literacy practitioners' skills and knowledge of effective community development approaches. Grass Roots Press' Adult Literacy Resources Catalogue for 2003 includes the following: Arnold, Burke, James, Martin \& Thomas, Educating for a Change; New England Literacy Resource Center's Civic Participation and Community Action Sourcebook: A Resource for Adult Educators; Carmen Rodriguez's Educating for Change: Community-based/Student-centered Literacy Programming with First Nations Adults; Pat Campbell and Barbara Burnaby's Participatory Practices in Adult Education, and Tools for Community Building: A Planning Workbook for Northern Canadian Community-Based Literacy. All of these resources appear worthy of evaluation.

\section{Organizational Development}

Organizational development strategies are of increasing relevance to health and literacy action since health promoters began to take a "settings approach" in which health and personal capacity are improved in workplaces, families and other environments where people live, work, learn and play. ${ }^{95}$ Organizational development strategies should include staff health promotion programs as well as means of promoting the health and well-being of learners and clients. Schools, school boards, public health offices and other organizations are now taking advantage of the change management literature from the private sector. All of these initiatives deserve rigorous evaluation with respect to impact on literacy and health.

In October 1999, Community Literacy of Ontario produced an impressive manual, Helping your Organization Flourish in the 21st Century, based on the thoughts and research of organizational change scholars and futurists including David Foot, Nuala Beck, Faith Popcorn, Den Balmer, Peter Drucker and organizations such as Statistics Canada, the Canadian Aging Network, the Angus Reid Group, the Canadian Centres for Philanthropy, the Canadian Advisory Council on the Information Highway, the Association of Colleges of Applied Arts and Technology, and the Conference Board of Canada. ${ }^{96}$

Similarly, in the health field, approaches to promoting health through organizational change have been developing. Skinner ${ }^{97}$ has developed a number of tools to aid managers of health-care organizations to help their organizations become more health promoting for their own employees as well as their clients. He used some of these tools while merging three departments into one Department of Public Health Sciences at the University of Toronto. He has also used some of these tools in the development of a TeenNet project. Information is beginning to emerge on the impact of such tools and strategies on emotional well-being, absenteeism and other outcomes. Ronson and Andrews ${ }^{98}$ described the profound impact on organizational culture and employee morale of an intensive change management strategy that addressed the strategy, structure, skills and culture at a nurse's union. However, little research is available concerning the impact of such organizational development programs on health, health literacy and literacy.

\section{Policy Development}

The potential of law and litigation (e.g., privacy laws, consent) as a means to reduce the difficulties of patients and consumers with low literacy is of increasing interest. ${ }^{99}$ There are, however, very few published studies on the effectiveness of this approach in relation to literacy and health though policy development in this area is increasing. For example, health literacy is 
gaining recognition by health-care accreditation bodies. In Canada, the Achieving Improved Measurement (AIM) accreditation program of the Canadian Council on Health Services Accreditation, sets standards for hospitals and health-care facilities. Several criteria relate to the need for patients and their families to be well informed and involved as active participants and to demonstrate that they understand the information provided. They do not use the term "literacy" but refer to "client's abilities", "clients with special needs" and "clients' level of education". They state that health information must be easy to read and use. ${ }^{22}$ Thus, one of the eight themes that emerged from the field at the national workshop was "influencing, developing and evaluating policy related to literacy and health." ${ }^{4}$ Relevant policy goes beyond legal aspects to plain language policies for organizations (e.g., the Ontario Literacy Coalition's new policy) and government policy for funding priorities.

In the United States, the Joint Commission on Accreditation of Health Organizations now requires that instructions be given at a level understandable to the patient. ${ }^{22}$ There is also interest in improving consent documents and the consenting process. ${ }^{100}$ Greater vigilance in health communications has been achieved through case law regarding obtaining informed consent from individuals with lower levels of literacy, and requirements imposed by the Joint Commission for Accreditation of Health Care Organizations and the National Committee for Quality Assurance about the nature and form of information used in patient education. ${ }^{101}$ "Health literacy" is now stated as an objective in Healthy People 2010, the blueprint document used for both state and national planning. Objective 11.2 under the area of health communication is "to improve the health literacy of persons with inadequate or marginal literacy skills." ${ }^{29}$

Marcia Hohn ${ }^{101}$ has recently published an overview of policy issues and initiatives regarding health literacy. Policies that need to be in place to provide a firm foundation for literacy and health work, she says, include those ensuring secure funding, teacher training for integrating health content and handling potentially sensitive situations, support structures for information sharing, and interagency referrals. Hohn draws from a recent survey of state basic education directors in the US to show promising policies and efforts towards interagency collaboration for health literacy in Pennsylvania and California. ${ }^{22}$ Other states such as Virginia and Georgia have introduced incentives for integrating health into the programs for English language services, by training Adult Basic Education teachers on how to incorporate health content into existing programs, and by initiating health literacy classes taught jointly by literacy and health education teachers in various sites including hospitals, churches and public health agencies.

Another policy initiative is the government of Massachusetts' decision to allocate a portion of tobacco tax revenue to community-based adult education programs interested in addressing health topics and developing health-related curricula through a participatory process involving adult learners and teachers. At the same time, a model program called Health Education in Adult Literacy (HEAL) focussed on breast and cervical cancer education was supported by a private nonprofit agency and the Centers for Disease Control and Prevention.

Dr. Rima Rudd and colleagues from the Harvard School of Public Health investigated the work of the 31 adult learning centers that had received funding from either the tobacco tax monies or from the HEAL project. ${ }^{100}$ Thirty-one teachers from twenty-four cities were interviewed. Almost all reported that the topic of the health project was chosen based on learners' needs and interests. Although the tobacco tax did not mandate it, anti-tobacco projects were the most common. Nutrition, HIV/AIDS, substance use, cancer prevention, stress management, accessing the health-care system and parenting skills were other common topics. When teachers were asked to rate the extent to which students' health projects contributed to various skills, it became clear that compared to other topics, health projects were perceived as offering added value for the development of both hard skills, such as reading, writing and math, and soft skills, such as speaking and presentation skills, dialogue and discussion. They also indicated that health projects contribute more to learner participation, motivation and interest.

\section{Combined Approaches}

Combined approaches appear to be particularly effective in addressing issues related to literacy and health. In addition, multilevel approaches based on ecological models increasingly are being put forward as being worthy of further exploration. For example, a recent US Institute of Medicine publication on social science and behavioural research to improve the public health recommended that: "[r]ather than focusing on a single or limited number of health determinants, interventions on social and behavioral factors should link multiple levels of influence (i.e., individual, interpersonal, institutional, community and policy levels)."102

\section{Conducting cost/benefit analyses}

Some progress has been made in assessing the economic cost of low literacy to Canada in other sectors. The Canadian Business Task Force on Literacy (1988) estimated that the annual cost to Canadian businesses from lost productivity due to low literacy was $\$ 4$ billion. ${ }^{45}$ In a Conference Board of Canada survey, DesLauriers ${ }^{103}$ found that of Canadian businesses with 50 or more employees, about $70 \%$ experienced some problems in their operations as a result of literacy issues in the workplace. Problems were most serious for the acquisition of new or advanced skills, training in general and the introduction of new technology. Negative impacts most frequently mentioned were productivity losses, errors in inputs and processes, reduced product quality, and problems in job reassignment. Less frequently mentioned difficulties included health and safety problems, higher job turnover rates and absenteeism. ${ }^{104}$ Both literacy and numeracy play a significant role in explaining labour market outcomes, even after years of schooling are accounted for. ${ }^{62}$

The costs of health-care delivery, however, related to direct and indirect impacts of literacy still need to be ascertained. ${ }^{6,42}$ Medical outcomes and economic costs of interventions need to be better understood..$^{28}$ As noted above, evidence to date suggests a link between literacy and increased health-care costs, ${ }^{7}$ at least in the US. However, research on this topic has been lacking in Canada. In addition, we also need to understand what politicians and decision-makers understand about lit- 
eracy and health and what can influence them. ${ }^{4}$

\section{Studying literacy and health within Aboriginal and Francophone communities}

There is a need to better understand and respect the relationship between literacy and culture in Aboriginal communities and the impact of literacy and literacy programs on health and healing. ${ }^{4}$ Investment in Aboriginal literacy development will ensure Canada's Aboriginal peoples have the resources they need to thrive as communities and as full participants and contributors to Canada's future economic and social prosperity. The Aboriginal population reached its lowest point at the turn of the twentieth century, but is now growing twice as fast as the overall Canadian population. Health and education status of this group is very different from that of mainstream groups. Twice as many registered Indians had less than Grade 9 education in 1996 as other Canadians. ${ }^{105}$ Their health status is also more severe. Four centuries of colonization - being stripped of their land, religion, culture and autonomy - have taken their toll. Though there has been improvement in recent years, the Aboriginal mortality rates were still almost 1.5 times higher than the national rate in 1996-97. ${ }^{106}$ Unique programs for this group deserve careful consideration. According to Dr. Eileen Antone, there is very little understanding of, or funding support for Aboriginal adult education programs that include intergenerational literacy participation and practices, which may be more helpful than non-Aboriginal models of schooling. ${ }^{107}$ Thus, the national workshop endorsed research on literacy and health in the Aboriginal community as a priority. ${ }^{4}$

The workshop participants also agreed that priority should be assigned to the study of literacy and health within the francophone community. According to Dr. Margot Kaszap from Laval University, a participant in the workshop and one of the co-investigators in the SSHRC project, literacy and health within the francophone community are significantly different from the anglophone community because of different cultural views of literacy and of health. Thus, to understand these differences requires special efforts. Like the
Aboriginal peoples, Canadians of French descent have official status enshrined in Canada's constitution and must therefore have their unique issues identified and considered.

With regard to other cultural groups, the early Southam study shed light mainly on the literacy problem of Canadian-born citizens of European descent. ${ }^{10}$ The problem among foreign-born Canadians was not so surprising and received less attention as a result. Further investigation suggests that the burden of need for help with literacy skills may currently lie with immigrants. New immigrants are among the most vulnerable populations in Canada. Some researchers suggest that for many, health actually deteriorates after they arrive (personal communication, Morton Beiser, August 2003). Of the $22 \%$ of Canadians at IALS level 1, most are people whose first language is neither English nor French, and people over 55. ${ }^{108}$ Those most likely to express a need for literacy programs in the national surveys to date are new immigrants. ${ }^{51}$ In the LSUDA study, more than twice as many foreign-born readers at levels 1 and 2 reported dissatisfaction with their skills. Those most likely to express satisfaction with their literacy skills are Canadian-born. Of Canadian-born people, $87 \%$ of women and $80 \%$ of men with the lowest literacy skills (levels 1 and 2) report satisfaction, while only $59 \%$ of foreignborn women and $50 \%$ of foreign-born men do so. ${ }^{75}$ More Canadian-born women and men with low literacy may have developed coping mechanisms in their daily activities and be reluctant to join programs that label them, reveal their deficiencies, and remind them of past frustrations with schooling.

A better understanding of the unique situation of new Canadians interested in literacy programs is needed. We also need to better understand what are the effective messages and methods of delivery in terms of different ethnic groups and multiliteracies. ${ }^{4}$ Foreign-born women and men with low literacy are less likely to be burdened by shame about low skills in English or French, but are more likely to have less time to attend classes. A greater percentage of foreign-born Canadians with low literacy skills participate in the workforce. Of all women in the workforce testing at the two lowest levels on the IALS survey, $52 \%$ are foreign-born though they represent only $17 \%$ of the female workforce. Foreignborn males represent $18 \%$ of the workforce and $34 \%$ of the men in the workforce who have low literacy levels 1 and $2 .^{75}$ According to literacy advocate Susan Sussman, most literacy programs are not designed to attract learners who fit the level 1 IALS demographic profile (immigrants and seniors). "Level One learners who need the most help and have the most difficulty learning often receive the least amount of instruction from the least qualified instructors." ${ }^{108}$ (p.9)

One of the key problems appears to be that literacy programs funded through the federal and provincial governments are expected to serve native speakers of French or English only. It is held that the Ministry of Culture and Immigration funds English and French as a second or other language programs for immigrants, and therefore literacy programs funded through other ministries (HRDC, Ministry of Training, Colleges and Universities, Ministry of Education) should only serve native speakers of English and French. Even the resource centers for literacy and English for Speakers of Other Languages classes are housed separately in Ontario despite significant overlap in types of resources needed. AlphaPlus Centre, the largest collection of literacy materials in Ontario, has recently moved its ESOL collection to the Metropolitan Toronto Reference Library. Sussman is not the only literacy worker that finds this situation troubling. Frontline workers are known to hide the fact that their classes mix native speakers of English and ESOL learners for fear of reprisal from their superiors.* Yet literacy workers report that new Canadians and native Canadians benefit from each other's presence in a shared classroom. ${ }^{*}$ Potential benefits of work in health literacy to Canadians of English and French origins as well as immigrants need to be better understood. For example, Canada could gain opportunities to provide health-care information, support and education internationally through better provision of health literacy opportunities for its own immigrants. The need for better interministerial cooperation in this regard is most apparent. Research on this issue could

Personal communication, literacy workers at August 2003 literacy conference, OISE/UT. 
help determine the extent of the problem and suggest steps towards a solution.

\section{Studying the relationship between literacy, life-long learning and health}

One of the key recommendations of the first OPHA report is "the creation of a major shift in the education system to allow for life-long learning. This would establish a drop-in - drop-out philosophy allowing people to acquire the skills they need when they need them." ${ }^{5}$ (p.34) This theme has gained momentum recently in Canada. Calamai coined the phrase The Three L's - Literacy and Life-Long Learning in an address to the Westnet 2000 Conference in Calgary. ${ }^{109}$ According to the Canadian Health Network, ${ }^{110}$

"...thanks in part to the growth of information and communication technologies, participation in adult education in Canada has exploded during the past 40 years. In 1960, only about $4 \%$ of Canadians over the age of 17 were thought to be taking any kind of course provided by an educational institution. Twenty years later, that number had increased to 20 percent. By the early 1990s, about 35 percent of Canadian adults were thought to be taking enrichment courses."

The Movement for Canadian Literacy, the hub of Canada's literacy network, has recently advocated for a National Literacy Action Agenda that is grounded in a lifelong learning strategy. They suggest that such an agenda be a key part of the federal government's new "innovation agenda" supported by Industry Canada and HRDC (see www.innovationstrategy.gc.ca). The Ontario Ministry of Education defines literacy education as (p.9): ${ }^{25}$

"...part of a process or cycle of life-

long learning, based on life experi-

ence, shared knowledge, and decision-

making by learners supported by their

instructors. Literacy education con-

tributes to the development of self

knowledge and critical thinking skills.

In turn, this development empowers

individuals and communities."

The recent national workshop on literacy and health research thus supported this direction, in concluding that "studying the impact of literacy and life-long learning on health" was one of the top four priorities. $^{10}$
An agenda for life-long learning may better address new understandings about multiple literacies and encourage learners previously held back by stigma. A Canadian Federation of Labour Education Coordinator provides the following description of previous counter-productive initiatives: ${ }^{11}$

"Human nature is such that a statistical focus on skill deficiencies make it more challenging.... Many people have the impression that a shockingly large percentage of the workforce sign their name with an $\mathrm{X}$ and can't add two plus two. Even worse is the impression that critical thinking skills, among those who have difficulty reading or writing, are marred. These, and similar myths, act as barriers to those who wish to improve their basic skills. Literacy should be framed within an empowering paradigm that highlights opportunities and choices for people. Unfortunately, much of the print generated has been devoid of empowerment. The blatant fostering of diseaseladen image (e.g., "stamping out the epidemic of illiteracy") is one such counterproductive example. It is not helpful when literacy is promoted wittingly or unwittingly - as the predominant solution to Canada's economic woes. A balanced viewpoint recognizes that the skills of workers are one of many factors that affect economic growth. Equally pertinent components include business investment in new equipment, work processes (that is, the way work is structured and jobs are designed), fiscal policy, and the amount of money allocated to training."

An agenda for life-long learning could begin to treat adults and teenagers on more similar terms and make high schools or "community education centres" welcoming and appealing to the young and old who are "ready to learn" (Saskatchewan is calling for renaming schools as "community learning centres" in their document Schools Plus and for creating a paradigm shift in the way schools are organized). It would also go some way towards reducing the stigma of dropping out, and to reducing the number of students who are not engaged in their school work, if alternatives such as extended co-op placements can be found for them. Such innovations in life-long learning provide valuable opportunities for studying the role of literacy in health.

\section{CONCLUSION}

Much progress has been made by healthservice providers in Canada in addressing literacy and health by raising awareness of the issue among health workers and disseminating plain language guides and health education materials. Progress has also been made in supporting non-medical aspects of the issue, encouraging literacy practitioners to help address it, and developing collaborations between health and literacy workers. Access to health information with reduced reliance on print and increasing use of new technologies has improved. But, due to several important social trends, the issue is likely to become more and more important and further research will be needed.

This literature review leads to the conclusion that additional research is needed with respect to virtually all of the areas covered by the conceptual framework. We need to know more about the relationships between general literacy, health literacy and other kinds of literacies, about the relationships between various kinds of literacies and health and quality of life outcomes, about the determinants of literacy and health literacy, as well as the effectiveness of various kinds of actions to improve health though improving literacy. We also need more cost-benefit analyses, more studies that consider the unique circumstances of the Aboriginal and francophone communities and culturally diverse and challenged groups, and more study of the relationship between literacy, life-long learning and health.

It is clear that research in literacy and health can help us spend our scarce health care dollars more efficiently. There are pockets of very promising work being done across the country, but there are huge gaps in between, with very little knowledge of what is being done elsewhere and what works best. Research of this nature can help span the divides between traditional jurisdictions of work for improving the lives of Canadians and have an impact on effective use of government spending in education as well as health care. To this end, based on this review of the evidence and discussion at the Think-Tank in 
September 2003, we would make the following recommendations:

1. That CIHR, SSHRC and the Canadian Health Services Research Foundation develop a joint strategic initiative on literacy and health based on the priorities and information needs identified in this article. Such an initiative should fund both research and capacity development.

2. That federal and provincial governments develop and implement policies and programs related to literacy and health and ensure that they are evaluated appropriately.

3. That non-governmental agencies such as the CPHA and the members of the NLHP form partnerships with researchers to ensure that their initiatives in literacy and health are evaluated appropriately.

4. That community agencies and health and literacy practitioners form partnerships with researchers to evaluate literacy and health initiatives and conduct participatory research on literacy and health.

5. That researchers and research organizations, such as the Canadian Consortium for Health Promotion Research, collaborate with research funding agencies, governments, non-governmental agencies and community agencies to develop an infrastructure for the evaluation of literacy and health initiatives using a participatory approach.

Clearly, movement in these directions can benefit all Canadians. We should not miss the opportunity to advance the field of literacy and health in Canada.

\section{REFERENCES}

1. Ontario Public Health Association and Frontier College. Literacy and Health Project Phase One: Making the World Healthier and Safer for People Who Can't Read. OPHA and Frontier College, 1989. Available from: http://www.opha.on.ca/ resources/literacy1summary.pdf.

2. Breen MJ. Partners in Practice: Literacy and Health Project Phase Two. Toronto, ON: OPHA and Frontier College, 1993.

3. Rootman I, Gordon El-Bihbety D, Frankish J, Hemming H, Kaszap Langille M, Quantz D, Ronson B. National Literacy and Health Research Program Needs Assessment and Environmental Scan. Ottawa, ON: Canadian Public Health Association, 2002. Available from: http://www.nlhp.cpha.cal clhrp/needs_el cover.htm.

4. Canadian Public Health Association. Literacy and Health Research Workshop: Setting Priorities in Canada, Final Report. Ottawa, ON: CPHA, 2003. Available from: http://www.nlhp.cpha.ca/ clhrp/index_e.htm\#workshop.

5. Perrin B, et al. Literacy and Health - Making the Connection: The Research Report of the Literacy and Health Project Phase One: Making the World Healthier and Safer for People Who Can't Read. OPHA and Frontier College, 1989. Available from: http://www.opha.on.ca/resources/ literacy1 research.pdf.

6. Rudd RE, Moeykens BA, Colton T. Health and literacy: A review of medical and public health literature. NCSALL: The Annual Review of Adult Learning and Literacy 1999;(1):ch.5.

7. Institute of Medicine. Health Literacy: A Prescription to End Confusion. Washington, DC: The National Academies Press, 2004

8. United Nations Educational, Scientific and Cultural Organization. Functional Literacy: Why and How. Paris, France: UNESCO, 1970.

9. Nafziger DH, Thompson RB, Hiscox MD, Owen TR. Tests of Functional Adult Literacy: An Evaluation Of Currently Available Instruments. Portland, OR: Northwest Regional Educational Laboratory, 1976.

10. Calamai P. Broken Words: Why Five Million Canadians are Illiterate: A Special Southam Survey. [Internet article]. 1987. Available from: www.nald.ca/fulltext/Brokwork/.

11. Kirsch IS, Jungeblut A, Jenkins L, Kolstad A. Adult Literacy in America: A First Look at the Results of the National Adult Literacy Survey (NALS). Washington, DC: National Center for Educational Statistics, U.S. Department of Education, 1993.

12. Organisation for Economic Co-operation and Development, Statistics Canada. Literacy, Economy and Society: Results of the First International Literacy Survey. Organisation for Economic Co-operation and Development Paris, Minister of Industry - Ottawa, 1995.

13. Statistics Canada. Reading the Future: A Portrait of Literacy in Canada. Ottawa: Statistics Canada, 1996. Available from: http://www.nald.ca/nls/ials/ialsreps/high1.htm.

14. Education Quality and Accountability Office Ontario Secondary School Literacy Test Report of Provincial Results. Toronto, ON: EQAO, 2003. Available from: http://www.eqao.com.

15. Freire P. Pedagogy of the Oppressed. Harmondsworth, UK: Penguin, 1972.

16. Education Development Center. Literacy: Tools for understanding and action. Mosaic 2000;2(3). Available from: http://main.edc.org/ Mosaic?Mosaic2/intro.asp.

17. Sticht T. Literacy and Vocational Competency. Occasional Paper No. 39, National Center for Research in Vocational Education. Columbus, OH: Ohio State University, 1978.

18. World Health Organization. Ottawa Charter for Health Promotion. Geneva, Switzerland: World Health Organization, 1986.

19. Akiwenzie-Damm, K. Native Literacy a Healing Energy. Owen Sound, ON: Ontario Native Literacy Coalition, 1998.

20. Young DE, Smith LL. The Involvement of Canadian Native Communities in Their Health Care Programs: A Review of the Literature since the 1970s. Edmonton, AB: University of Alberta, Canadian Circumpolar Institute and Centre for the Cross-Cultural Study of Health and Healing, 1992.

21. Ontario Native Literacy Coalition. Empowering the Spirit, Ensuring Survival Phase II. Field Development Moving Towards Action. Owen Sound, ON: Ontario Native Literacy Coalition, 2003.

22. Shohet L. Health and Literacy: Perspectives in 2002. Montreal: Centre for Literacy of Quebec, 2002. Available from: http://www.staff.vu.edu.au/ alnarc/onlineforum/AL pap shohet.htm.

23. Leu DL Jr. Developing New Literacies: Using the Internet in Content Area Instruction [Internet article] [cited 2001 August 18]. Available from: http://web.syr.edu/ djleu/content.htm.

24. Centre for Literacy of Quebec [homepage on the Internet]. Available from: http://www.centreforliteracy.qc.ca/.
25. Parkland Regional College. Reaching the Rainbow: Aboriginal Literacy in Canada. Melville, SK: Parkland Regional College, 1998.

26. George NP. Research on (Aboriginal) Literacy in Australia, 2002. Available from: www.nald.ca/fulltext/abo-aus/.

27. Ratzan SC. Health literacy: Communication for the public good. Health Promot Int 2001;16:207-14.

28. American Medical Association Ad Hoc Committee on Health Literacy. Health literacy: Report of the Council on Scientific Affairs. JAMA 1992;281(6):552.

29. United States Department of Health and Human Services, Office of Disease Prevention and Health Promotion. Healthy People. Washington, DC: US Dept. of Health and Human Services, 2000. Available from: http://www.health.gov/healthypeople.

30. Ratzan SC, Parker RM. Introduction. In: Selden CR, Zorn M, Ratzan SC, Parker RM (Eds.), National Academies of Medicine Current Bibliographies in Medicine: Health Literacy. Bethesda, MD: National Institutes of Health, U.S. Department of Health and Human Services, 2000.

31. Williams MV, Parker RM, Baker DW, Parikh NS, Pitkin K, Coates WC, et al. Inadequate functional health literacy among patients at two public hospitals [comment]. JAMA 1995;(274)21:1719-20.

32. Kickbusch I, Nutbeam D. Health promotion glossary. Health Promot Int 1998;13:349-64.

33. Nutbeam D. Health literacy as a public health goal: A challenge for contemporary health education and communication strategies into the $21 \mathrm{st}$ century. Health Promot Int 2000;15(3):183-84.

34. Tones K. Health literacy: New wine in old bottles? Health Educ Res 2002;17(3):287-90.

35. Rootman I. Literacy and health promotion. OPHE Bulletin 2002. Available from: http://www.ohpe.ca.

36. Parker RM, Baker DW, Williams MV, Nurss JR. The test of functional health literacy in adults: A new instrument for measuring patients' literacy skills. J Gen Intern Med 1995;10(10):537-41.

37. Baker DW, Parker RM, Williams MV, Clark WS, Nurss J. The relationship of patient reading ability to self-reported health and use of health services. Am J Public Health 1997;87(6):1027-30.

38. Baker DW, Gazmararian JA, Sudano J, Patterson M, Parker RM, Williams MV. Health literacy and performance on the Mini-Mental State Examination. Aging o Mental Health 2002;6(1):22-29.

39. Roberts P, Fawcett G. At Risk: A Socio-economic Analysis of Health and Literacy among Seniors. Ottawa, ON: Statistics Canada, 1998.

40. Guerra CE, Shea JA. Functional health literacy: Co-morbidity and health status. I Gen Intern Med 2003;18(Suppl 1):174.

41. Kalichman SC, Ramachandran B, Catz S. Adherence to combination antiretroviriaral therapies in HIV patients of low literacy. J Gen Intern Med 1999; 5:267-73.

42. Health Canada. How does literacy affect the health of Canadians? 2003. [Internet article] Available from: http://www.phac-aspc.gc.ca/ ph-sp/phdd/literacy/literacy.html.

43. Schillinger D, Grumbach K, Piette J, Wang F, Osmond D, Daher C, et al. Association of health literacy with diabetes outcomes. JAMA 2002;288(4):475-82.

44. Sarginson RJ. Literacy and Health: A Manitoba Perspective. Winnipeg, MB: Literacy Partners of Manitoba, 1997.

45. Canadian Business Task Force on Literacy, Measuring the costs of illiteracy in Canada. In: Literacy and Health: A Forum For Collaboration. Calgary, AB: Calgary Adult Literacy Awareness Project, 1998. 
46. Edwards C. Due diligence: The challenge of language and literacy. Accident Prevention 1995;42(6):18-21.

47. Hawthorne G. Pre-teenage drug use in Australia: Key predictors and school-based drug education. J Adolesc Health 1997;20(5):384-95.

48. Gazmararian JA, Baker DW, Williams MV, Parker RM, Scott TL, Green DC, et al. Health literacy among Medicare enrollees in a managed care organization [comment]. JAMA 1999;282(6):527.

49. Federal, Provincial and Territorial Advisory Committee on Population Health. Toward a Healthy Future. Ottawa, ON: Health Canada, 1999.

50. Weiss BD, Blanchard JS, McGee DL, Hart G, Warren B, Burgoon $\mathrm{M}$, et al. Illiteracy among Medicaid recipients and its relationship to health care costs. J Health Care Poor Underserved 1994:5(2):99-111.

51. Statistics Canada. Adult Literacy in Canada: Results of a National Study. Ottawa, ON: Minister of Industry, Science and Technology, 1991.

52. Parker RM, Ratzan SC, Lurie N. Health literacy: A policy challenge for advancing high quality health care. Health Aff 2003;22(4):147.

53. Scott TL, Gazmararian JA, Williams MV, Baker DW. Health literacy and preventive health care use among Medicare enrollees in a managed care organization. Med Care 2002;40(5):395-404.

54. Bennett CL, Ferreira MR, Davis TC, Kaplan J, Weinberger M, Kuzel T, et al. Relation between literacy, race, and stage of presentation among low-income patients with prostate cancer. J Clin Oncol 1998;16(9):3101-104.

55. Baker DW, Gazmararian JA, Williams MV, Scott T, Parker RM, Green D, et al. Functional health literacy and the risk of hospital admission among Medicare managed care enrollees. Am J Public Health 2002;92(8):1278-83.

56. Davis TC, Meldrum H, Tippy PKP, et al. How poor literacy leads to poor health care. Patient Care 1996;30(16):94-124.

57. Brez SM, Taylor M. Assessing literacy for patient teaching: Perspectives of adults with low literacy skills. JAdv Nurs 1997;25:1040-47.

58. Renwick R, Brown I, Raphael D. Person-Centered quality of life: Contributions from Canada to and international understanding. In: Keith KD, Schalock RI (Eds), Cross-Cultural Perspectives on Quality of Life. Washington, DC: American Association on Mental Retardation, 2000

59. Grossman M, Kaestner R. The effects of education on health. In: Behermann R, Stacey N (Eds.), The Social Benefits of Education. Ann Arbor, MI: University of Michigan Press, 1997;69-123.

60. Weiss BD. Health literacy: An important issue for communicating health information to patients. Ch Med J 2001;64(11):603-608.

61. Organisation for Economic Co-operation and Development, Statistics Canada. Literacy in the information age: Final report of the International Adult Literacy Survey. [cited : 2000 Dec 27]. Available from: www.statcan.cal english/freepub/89-588-XIE/about.htm.

62. Charette MF, Meng R. The determinants of literacy and numeracy and the effect of literacy and numeracy on our market outcomes. Canadian Journal of Economics/Revue canadienne d'économique 1998;13(3). [cited 2003 Aug 13]. Available from: www.nald.ca/fulltext/pat/ Charette/page1.htm.

63. Mustard F, McCain MN. Early Years Study. Toronto, ON: Queen's Printer for Ontario, 1999.

64. Begley S. Your child's brain. Newsweek 1996;Feb.19:54-62.

65. Schweinhart LJ, Barnes HV, Weikart DP, Barnett WS, Epstein AS. Significant Benefits: The High/Scope Perry Preschool Study through Age 27. Ypsilanti, MI: High/Scope Press, 1993.
66. The World Bank Group. The ABC's of EDC [Internet article] [cited 2003 Dec 6]. Available from: http://www.worldbank.org/children/ braindev.html.

67. Baker DW, Gazmararian JA, Sudano J, Patterson, M. The association between age and health literacy among elderly persons. J Gerontol B-Psychol Sci Soc Sci 2000;55(6):S368-74.

68. Baker DW, Parker RM, Williams MV, Clark WS. Health literacy and the risk of hospital admission [comment]. J Gen Intern Med 1988;13(12):850-51.

69. Breen MJ. Promoting literacy, improving health. In: Canada Health Action: Building on the Legacy. V2 Adults and Seniors. Ottawa, ON: National Forum on Health, 1998.

70. Ontario Association for Children and Adults with Learning Disabilities. Critical Issues Register. Inglis E (Ed.). Toronto, ON, 1986.

71. Puchner LD. Early Childhood, Family, and Health Issues in Literacy: International Perspectives. Philadelphia, PA: NCAL, International Paper, 1993.

72. Totten M, Quigley P. Bullying, School Exclusion and Literacy. [unpublished discussion paper]. Ottawa, ON: Canadian Public Health Association, 2003.

73. Davies R. Men for Change. Halifax, NS: Private correspondence, 1995.

74. Daniel S, Kennedy B, Kawachi I. Justice is good for our health: How greater economic equality would promote public health. Boston Review 2000; Feb/March. [cited 2005 Mar 18]. Available from: http://www.bostonreview.net/ BR25.1/daniels.html.

75. Boyd M. Gender, nativity and literacy: Proficiency and training issues. In: Adult Literacy in Canada: Results of National Study. Ottawa, ON: Statistics Canada, 1991;86-94.

76. Organisation for Economic Co-operation and Development. Knowledge and Skills for Life: First Results from the OECD Programme for International Student Assessment. 2001.

77. Beers BB, McDonald VJ, Quistberg DA, Ravenell KL, Asch DA, Shea JA. Disparities in health literacy between African and non-African American primary care patients. J Gen Intern Med 2003;18(Suppl 1):167.

78. DeWit DJ, Akst L, Braun K, Jelley J, Lefebver L, McKee C, et al. Sense of School Membership: A Mediating Mechanism Linking Student Perceptions of School Culture with Academic and Behavioural Functioning: Baseline Data Report of the School Culture Project. Toronto, ON: Centre for Addiction and Mental Health, 2002.

79. Davis TC, Mayeaux EJ, Fredrickson D Bocchini JA Jr, Jackson RH, Murphy PW. Reading ability of parents compared to reading level of pediatric patient education materials. Pediatrics 1994;93(3):460-68.

80. Meade CD, McKinney WP, Barnas GP Educating patients with limited literacy skills: The effectiveness of printed and videotaped materials about colon cancer. Am J Public Health 1994;84(1):199-121.

81. Wydra EW. The effectiveness of a self-care management interactive multimedia module. Oncol Nurs Forum 2001;28(9):1399-407.

82. Michielutte R, Bahnson J, Dignan MB, Schroeder EM. The use of illustrations and narrative text style to improved readability of a health education brochure. J Cancer Educ 1992;7(3):251-60.

83. Farkas CS, Glenday PG, O'Connor PJ, Schmeltzer J. An evaluation of the readability of prenatal health education materials. Can J Public Health 1987;78:374-78.

84. Smith JL, Haggerty J. Literacy in primary care populations: Is it a problem? Can J Public Health 2003;94(6):408-12.
85. Schillinger D, Bindman A, Wang F, Stewart A, Piette J. Functional health literacy and the quality of physician-patient communication among diabetes patients. Patient Education and Counseling 2004;52(3):315-23.

86. Jadad AR. Promoting partnerships: Challenges for the internet age. BMJ 1999;318:761-64.

87. Mulrow C, Bailey S, Sonksen PH, Slavin B. Evaluation of an audiovisual diabetes education program: Negative effects of a randomized trial of patients with non-insulin-dependent diabetes mellitus. J Gen Intern Med 1987;2(4):215-19.

88. Rothman RL, Pignone M. Malone R, Bryant B, DeWalt DA, Crigler B. A longitudinal analysis of the relationship between literacy and metabolic control in patients with diabetes [abstract]. J Gen Intern Med 2003;18(Suppl 1).

89. Davis TC, Fredrickson DD, Arnold C, Murphy PW, Herbst M, Bocchini JA. A polio immunization pamphlet with increased appeal and simplified language does not improve comprehension to an acceptable level. Patient Education and Counseling 1998;33(1):25-37.

90. Jones $S$. Literacy programming and the survey of literacy skills used in daily activities. In Statistics Canada, Adult Literacy in Canada: Results of a National Study. Minister of Industry, Science and Technology, 1991;100.

91. World Health Organization - European Working Group on Health Promotion Evaluation. Health Promotion Evaluation: Recommendations to Policymakers. Copenhagen, Denmark: WHO Regional Office for Europe, 1998

92. Hahn EA, Cella D. Assessment in Vulnerable Populations: Measurement Challenges and Recommendations. Arch Phys Med Rehabil 2003;84:(Suppl 2).

93. Wallerstein N, Sanchez-Merki V, Dow L. Freirian Praxiz in Health education and community organizing: A case study of an adolescent prevention program. In: Minkler M (Ed.), Community Organizing and Community Building for Health. New Brunswick, NJ: Rutgers University Press, 1997;195-211.

94. Action Read Community Literacy Centre. $A$ Dream that Walks: Goal Setting Stories. Guelph, ON: Garlic Press, 2000.

95. Poland B, Green L, Rootman I (Eds.), Settings for Health Promotion: Linking Theory and Practice. Thousand Oaks, CA: Sage Publications, 2000.

96. Herchmer B. Helping Your Organization Flourish in the 21st Century. Community Literacy of Ontario/Niagara Centre for Community Life \& Leadership, 1999.

97. Skinner H. Promoting Health through Organizational Change. San Francisco, CA: Benjamin Cummings, 2002.

98. Ronson B, Andrews N. Transformation: The Ontario Nurses' Association. Presentation to the Work Health Seminar Group, February 18, 1999.

99. Gordon D. MDs' failure to use plain language can lead to the courtroom. CMA 1996;155(8):1152-54

100. Rudd RE, Zachariai C, Daube, K. Integrating health and literacy: Adult educators' experiences. National Center for the Study of Adult Learning and Literacy Reports 1998;5.

101. Hohn MD. Literacy, health and health literacy: State policy considerations. Focus on Basics 2002;5(C).

102. Institute of Medicine (US), Committee on Capitalizing on Social Science and Behavioral Research to Improve the Public's Health, Division of Health Promotion and Disease Prevention. Promoting Health: Intervention Strategies from Social and Behavioral Research. Washington, DC: National Academy Press, 2001.

103. DesLauriers R. The Impact of Employee Illiteracy on Canadian Business. Report 58-90. Conference Board of Canada, 1990. 
104. O'Neil T, Sharpe A. Functional illiteracy: Economic costs and labour market implications. In: Statistics Canada, Adult Literacy in Canada: Results of a National Study Part 1. Ministry of Industry, Science and Technology, 1991.

105. Literacy Nova Scotia The Value of Literacy. [cited 2003 Dec 19]. Available from: http://www.nald.ca/literacyns/law03kit/value.htm.

106. Shah CP. The health of Aboriginal peoples. In: Raphael D (Ed.), Social Determinants of Health: Canadian Perspectives. Toronto, ON: Canadian Scholars' Press Inc., 2004;274

107. Antone EM. Aboriginal peoples: Literacy and learning. Literacies 2003;1(Spring):9-12.

108. Westell T. Why numbers? An interview with Susan Sussman. Literacies 2003:2(Fall): 9

109. Parkland Regional College. Reaching the Rainbow: Aboriginal Literacy in Canada. Melville: Parkland Regional College, 1988.

110. Canadian Health Network. Learning for Life: Adults go back to school [Internet article] [2003 Dec 19]. Available from: http://www.canadianhealth-network.ca/servlet/ContentServer?cid= $1061005578601 \&$ pagename=CHN RCS\%2FCHNResource\%2FCHNResourcePag eTemplate\&c=CHNResource

111. McLeod C. Literacy for workers: A labour perspective on basic skills. In: Adult Literacy in Canada: Results of a National Study. Ottawa, ON: Statistics Canada, 1991;83.
RÉSUMÉ

L'auteur de l'article fait une revue de la documentation actuelle et de la recherche sur le lien entre I'alphabétisme et la santé et dégage des priorités pour la recherche dans ce domaine au Canada. Parmi les sources d'information, mentionnons des documents repérés grâce à une analyse de I'environnement, la collection Alpha Plus et une recherche informatisée des documents récents. Cette information a ensuite été analysée au moyen d'un cadre conceptuel. Selon la revue, un alphabétisme limité a un impact direct et indirect sur la santé. Les familles sont à risque à cause de la difficulté qu'elles ont à lire les ordonnances médicales, les instructions des aliments pour bébé et le matériel d'éducation sur la santé et la sécurité. Les gens dont le niveau d'alphabétisme est peu élevé ont tendance à vivre et à travailler dans un environnement moins sain; ils ont plus de difficulté à trouver de l'emploi et à assurer la sécurité de leur revenu. Les déterminants de I'alphabétisme sont les suivants : éducation, développement de la petite enfance, vieillissement, conditions de vie et de travail, capacité/génétique individuelles, sexe et culture. Il convient de prendre des mesures afin d'améliorer le niveau d'alphabétisme et de santé par une combinaison d'éléments tels la communication, l'éducation et la formation, le développement communautaire, le développement organisationnel et l'élaboration de politiques. Certaines indications donnent à penser que les interventions de ce type ont un impact positif sur la santé, en particulier si elles sont combinées. L'élaboration de politiques et de programmes requiert une analyse approfondie des initiatives actuelles et davantage d'analyses coûts avantages et d'études qui mettent l'accent sur les différentes communautés culturelles. Un soin accru doit également être accordé aux tendances et aux besoins sociaux actuels. 